\title{
Munc13-1 Is Required for Presynaptic Long-Term Potentiation
}

\author{
Ying Yang and Nicole Calakos \\ Center for Translational Neuroscience, Departments of Medicine/Neurology and Neurobiology, Duke University Medical Center, Durham, North Carolina \\ 27710
}

Long-lasting forms of synaptic plasticity involve modification of presynaptic strength in many brain regions. Although a presynaptic site for expression is well established, the detailed molecular mechanisms that lead to sustained changes in neurotransmitter release remain unclear. Here, we use acute in vivo genetic manipulation of synaptic proteins to investigate the molecular basis for presynaptic long-term potentiation (LTP) at hippocampal mossy fiber synapses. Munc13 proteins are active zone proteins that are essential for synaptic vesicle priming and neurotransmitter release. Munc13 proteins also interact with RIM1 $\alpha$, an active zone protein required for presynaptic long-term plasticity. By taking advantage of the observation that the RIM-binding domain of Munc13 is separable from the domain that is required for neurotransmitter release, we selectively tested whether Munc13-1 is an effector for RIM1 $\alpha$ in presynaptic LTP. Our results provide the first evidence for the involvement of Munc13-1 in presynaptic long-term synaptic plasticity. We further demonstrate that the interaction between RIM1 $\alpha$ and Munc13-1 is required for this plasticity. These results advance our understanding of the molecular mechanisms of presynaptic plasticity and suggest that modulation of vesicle priming may provide the cellular substrate for expression of LTP at mossy fiber synapses.

\section{Introduction}

Neurotransmitter release via synaptic vesicle exocytosis is a central event in neuronal communication. It is restricted spatially to presynaptic active zones. Active zone proteins organize the docking and priming of synaptic vesicles, and mediate activity-dependent changes of release in short- and long-term forms of synaptic plasticity (Rizo and Rosenmund, 2008).

Munc13 proteins are a family of active zone proteins (Munc13-1, Munc13-2, Munc13-3, and Munc13-4). Munc13 proteins are required for neurotransmission; in the absence of Munc13 proteins, there is a complete loss of spontaneous and evoked synaptic transmission (Augustin et al., 1999; Rosenmund et al., 2002; Varoqueaux et al., 2002). The roles of Munc13-1 and 13-2 in basal release properties and short-term synaptic plasticity have been extensively studied. Current evidence supports an essential role for the MUN domain in vesicle priming (Basu et al., 2005; Stevens et al., 2005), a regulatory role for the $\mathrm{C}_{2}$ A domain in vesicle priming (Betz et al., 2001; Deng et al., 2011), and roles for the $\mathrm{C} 2$ domains, $\mathrm{C} 1$ domain, and calmodulin-binding (CaMb) sequence in short-term synaptic plasticity (Junge et al., 2004; Basu et al., 2007; Shin et al., 2010). The contributions of Munc13

\footnotetext{
Received May 6, 2011; revised July 1, 2011; accepted July 6, 2011.

Author contributions: Y.Y. and N.C. designed research; Y.Y. performed research; Y.Y. analyzed data; Y.Y. and N.C. wrote the paper.

Funding was provided by K02 (NS054840) and P01 (NS053862) grants from NINDS and a Ruth K. Broad Foundation Faculty Award in the Neurosciences. We thank Zachary Caffall, Yuanji Pan, and Samantha Tracy for outstanding technical assistance, Dr. Thomas Südhof for providing RIM1 $\alpha^{-1-}$ mice and RIM1 $\alpha$ CDNA, Dr. Christian Rosenmund for providing Munc13-1 CDNA, members of the Calakos laboratory for stimulating discussions, and Drs. Sandra Bajjalieh and Hélène Marie for critical readings of this manuscript.

Correspondence should be addressed to Nicole Calakos at the above address. E-mail: nicole.calakos@duke.edu. DOI:10.1523/JNEUROSCI.2276-11.2011

Copyright $\odot 2011$ the authors $\quad 0270-6474 / 11 / 3112053-05 \$ 15.00 / 0$
}

proteins to long-term forms of synaptic plasticity are much less studied. Munc13-2 knock-out mice have normal long-term presynaptic plasticity at mossy fiber synapses in the hippocampus (Breustedt et al., 2010). However, the involvement of Munc13-1, the major Munc13 protein in the brain, in long-term presynaptic plasticity has not yet been tested.

Presynaptic forms of long-term plasticity are widely expressed throughout the brain, having been described in regions such as the cortex, cerebellum, hippocampus, thalamus, amygdala, and striatum (García-Junco-Clemente et al., 2005; Heifets and Castillo, 2009). Presynaptic long-term potentiation (LTP) is associated with an increase in release probability (Weisskopf and Nicoll, 1995; Salin et al., 1996), but further understanding of the cellular basis for this change in release probability is not known. At the molecular level, presynaptic LTP is known to require protein kinase A, the synaptic vesicle protein, Rab3A, and the active zone protein, RIM1 $\alpha$ (Huang et al., 1994; Weisskopf et al., 1994; Castillo et al., 1997, 2002; Villacres et al., 1998; Fourcaudot et al., 2008). RIM $1 \alpha$ binds to the N-terminal $\mathrm{C}_{2} \mathrm{~A}$ domain of Munc13 (Betz et al., 2001; Dulubova et al., 2005) and can regulate priming through this interaction (Deng et al., 2011). In this study, we investigated whether Munc13-1 and its interaction with RIM1 $\alpha$ are involved in presynaptic LTP.

To do this, we took advantage of an approach we recently developed to probe the molecular mechanisms of presynaptic LTP (Yang and Calakos, 2010). We acutely expressed proteins in hippocampal granule cells using in vivo viral-mediated gene delivery and monitored the effects on mossy fiber LTP (mfLTP), a well characterized form of presynaptic LTP (Nicoll and Schmitz, 2005). We show that disruption of Munc13-1 function, by expressing either the RIM-binding domain of Munc13-1 or a RIM1 $\alpha$ 
protein that does not bind Munc13, inhibits mfLTP. Furthermore, disruption of RIM1 $\alpha$ 's ability to bind Munc13 also disrupts RIM1 $\alpha$ 's ability to rescue mfLTP in RIM1 $\alpha$ knock-out (KO) mice. These results identify for the first time, a role for Munc13 proteins in presynaptic LTP and further show that an interaction between Munc13-1 and RIM1 $\alpha$ underlies the requirement for Munc13-1 in mfLTP.

\section{Materials and Methods}

Plasmids and virus preparation. Rat RIM1 $\alpha$ cDNA was kindly provided by Dr. Thomas Südhof (Stanford University, Palo Alto, CA) and contains the $\Delta 83-105$ splice variant at splice site A (Wang et al., 1997). Rat Munc13-1 cDNA was kindly provided by Dr. Christian Rosenmund (Universitätsmedizin Berlin, Berlin, Germany) (Betz et al., 2001). Missense mutations (K144/146E) of RIM1 $\alpha$ cDNA were introduced using the QuikChange Site-Directed Mutagenesis Kit (Agilent Technologies). RIM1 $\alpha$ mutations were introduced to the cDNA in a shuttle vector before subcloning into pSINrep $\left(\right.$ nsP2S ${ }^{726}$ ) (kindly provided by Dr. Pavel Osten, Cold Spring Harbor Laboratory, Cold Spring Harbor, NY) (Kim et al., 2004). The N-terminal fragment of Munc13-1 (amino acids 1-451) was PCR amplified from Munc13-1 cDNA and subcloned into pSINrep (nsP2S $\left.{ }^{726}\right)$. An internal ribosomal entry sequence (IRES) and EGFP cDNA were subcloned from pSR5I2E (Marie et al., 2005) and inserted 3' of the synaptic protein cDNAs. Concentrated Sindbis viruses were generated as previously described (Yang and Calakos, 2010). Control virus expressed only EGFP downstream of the IRES sequence. Test viruses expressed synaptic protein CDNA upstream of the IRES and EGFP sequences. Minimum estimates of viral overexpression levels based on immunohistochemistry of RIM $1 \alpha$ indicate greater than 10 -fold increases over wild-type levels (data not shown). Viral identities were unknown to the investigator during in vivo injection, data acquisition, and analysis.

Mice. RIM $1 \alpha^{-1-}$ mice were provided by Dr. Thomas Südhof. Mice were generated and colony maintained as previously described (Schoch et al., 2002; Yang and Calakos, 2010). Wild-type mice were obtained from $\operatorname{RIM} 1 \alpha^{+/+} \mathrm{xRIM} 1 \alpha^{+/+}$or $\operatorname{RIM} 1 \alpha^{+/-}$ xRIM $1 \alpha^{+/-}$breeding; RIM $1 \alpha^{-1-}$ mice (KO) were obtained from RIM $1 \alpha^{-/-}$xRIM $1 \alpha^{-/-}$or $\operatorname{RIM} 1 \alpha^{+/-}$xRIM $1 \alpha^{-/-}$breeding. All parents of experimental subjects were obtained from the breeding colony, which was maintained exclusively by RIM $1 \alpha^{+/-}$xRIM $1 \alpha^{+/-}$mating.

Stereotaxic injection. Stereotaxic injection was performed as previously described (Yang and Calakos, 2010). Briefly, $50 \mathrm{nl}$ of concentrated Sindbis $\left(\mathrm{nsP} 2 \mathrm{~S}^{726}\right.$ ) virus was injected (flow rate of $23 \mathrm{nl} / \mathrm{s}$ ) into the dentate gyrus of the hippocampus bilaterally. Initial injection coordinates relative to bregma were anterior $2.00 \mathrm{~mm}$, mediolateral $1.20 \mathrm{~mm}$, dorsoventral $2.00 \mathrm{~mm}$. Five additional $50 \mathrm{nl}$ injections occurred each $0.05 \mathrm{~mm}$ during withdrawal of the injection cannula. Virus was delivered using Nanoject II (Drummond Scientific) and the cannula remained at each location for $1 \mathrm{~min}$ after infusion.

Electrophysiology. Acute transverse hippocampal slices $(300 \mu \mathrm{m})$ were prepared from mice $2-8 \mathrm{~d}$ after surgery. Infected slices were selected for
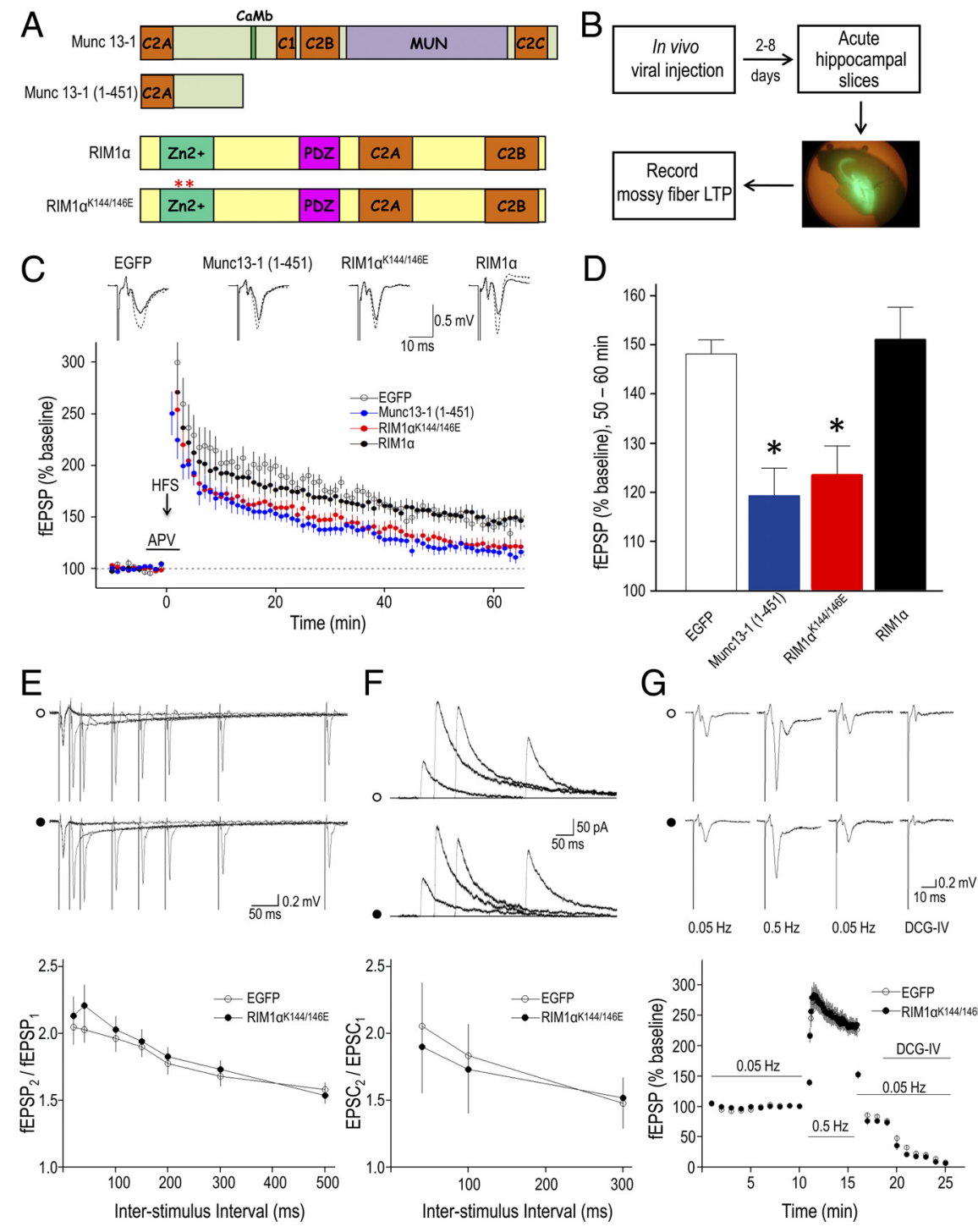

Munc13-1 and RIM1 $\alpha$-Munc13 interaction are involved in mossy fiber LTP. $\boldsymbol{A}$, Diagram of full-length and mutan ments in wild-type hippocampal slices with acute in vivo viral-mediated expression of proteins. Representative traces are an average of responses obtained over a $1 \mathrm{~min}$ period immediately before (solid trace) and $60 \mathrm{~min}$ after (dashed trace) tetanus. HFS min after tetanus. $\boldsymbol{E}$, Wild-type hippocampal slices expressing RIM1 $\alpha^{\mathrm{K} 144 / 146 \mathrm{E}}$ exhibit similar paired-pulse facilitation to those pressing control EGFP virus, at interstimulus intervals ranging from 20 to $500 \mathrm{~ms}$. Representative traces are an average of 5 Representative traces are an average of 10 sweeps. G, Wild-type hippocampal slices expressing RIM1 $\alpha^{\mathrm{K} 144 / 146 \mathrm{E}}$ exhibit similar frequency facilitation and sensitivity to DCG-IV to those expressing control EGFP virus. Representative traces are an average of five weeps. Sample sizes are as follows: C, D (slices/mice) —EGFP, 6/3; Munc13-1(1-451), 11/4; RIM1 $\alpha^{\text {K144/146E }}$, 13/5; RIM1 $\alpha, 13 / 9$; $\boldsymbol{E}, \boldsymbol{G}$ (slices/mice) —EGFP, 14/5; RIM1 $\alpha^{\mathrm{K} 144 / 146 \mathrm{E}}, 11 / 3 ; \boldsymbol{F}$ (cells/mice) —EGFP, 10/5; RIM1 $\alpha^{\mathrm{K} 144 / 146 \mathrm{E}}, 7 / 3$.

use if EGFP fluorescence was detectable in more than half of the area of the dentate gyrus viewed in the horizontal plane (Yang and Calakos, 2010). External recording solution contained the following (in $\mathrm{mM}$ ): 119 $\mathrm{NaCl}, 2.5 \mathrm{KCl}, 1.3 \mathrm{MgSO}_{4}, 2.5 \mathrm{CaCl}_{2}, 1.0 \mathrm{NaH}_{2} \mathrm{PO}_{4}, 26.2 \mathrm{NaHCO}_{3}$, and 10 D-glucose (saturated with $95 \% \mathrm{O}_{2}$ and $5 \% \mathrm{CO}_{2}$ ). Slices were perfused at $2 \mathrm{ml} / \mathrm{min}$ at room temperature during recordings. A monopolar stimulation electrode with $2 \mathrm{M} \mathrm{NaCl}$ was placed in a region of stratum granulosum with EGFP fluorescence. Mossy fiber responses were monitored at room temperature every $20 \mathrm{~s}$ by extracellular field potentials (fEPSPs) from the stratum lucidum in the CA3 area, or by NMDA receptormediated EPSCs (NMDAR-EPSCs) from CA3 pyramidal cells in wholecell configuration at $+40 \mathrm{mV}$ in the presence of NBQX $(10 \mu \mathrm{M})$ and picrotoxin $(100 \mu \mathrm{M})$. Extracellular recording pipette contained $2 \mathrm{M} \mathrm{NaCl}$. 

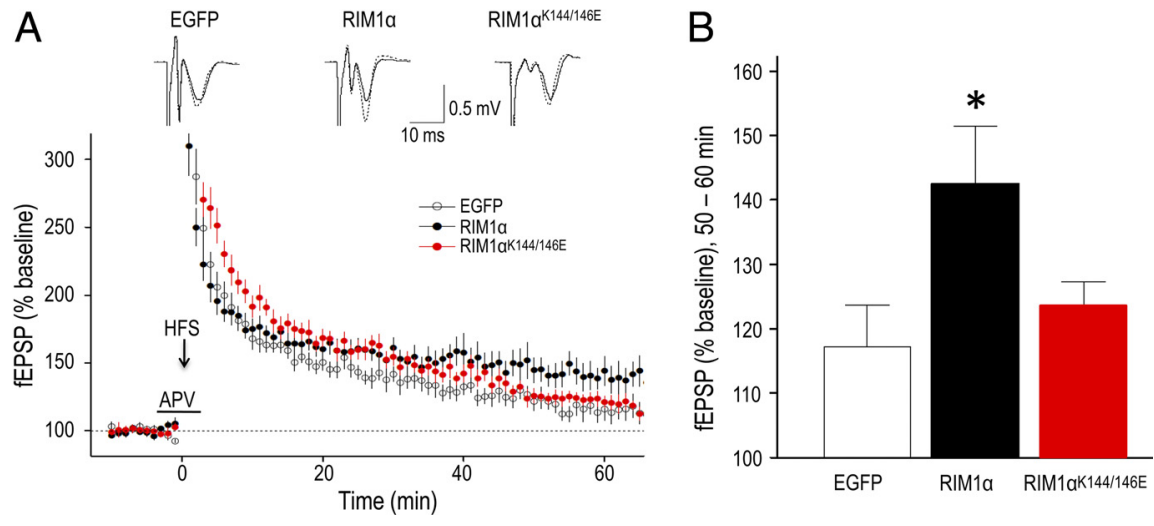

Figure 2. RIM1 $\alpha$-Munc13 interaction is required for rescue of mfLTP in RIM1 $\alpha$ KO mice. $A$, Summary of mfLTP experiments in RIM1 $\alpha$ KO hippocampal slices with acute in vivo viral-mediated expression of proteins. Representative traces are an average of three responses obtained over $1 \mathrm{~min}$ from periods immediately before (solid trace) and $60 \mathrm{~min}$ after (dashed trace) tetanus. $\boldsymbol{B}$, Mean level of mfLTP measured 50-60 min after tetanus. Sample size are as follows (slices/mice): EGFP, 8/6; RIM1 $\alpha, 11 / 6$; $\mathrm{RIM} 1 \alpha^{\mathrm{K} 144 / 146 \mathrm{E}}, 10 / 6$. HFS indicates high-frequency stimulation. Bar indicates period during which APV is present.

Whole-cell recording pipette internal solution ( $\mathrm{pH} 7.2 ; 297 \mathrm{mOsm})$ contained the following (in $\mathrm{mm}$ ): 123 cesium gluconate, $10 \mathrm{CsCl}, 8 \mathrm{NaCl}, 1$ $\mathrm{CaCl}_{2}, 10$ EGTA, 10 HEPES, and 10 glucose. Baseline stimulation intensity was adjusted to yield fEPSPs between 0.4 and $0.7 \mathrm{mV}$ or NMDAREPSCs between 50 and $300 \mathrm{pA}$. Mossy fiber contribution to responses was determined at the end of each experiment by sensitivity to pharmacological blockade by DCG-IV, a group II metabotropic glutamate receptor agonist that selectively suppresses mossy fiber synaptic transmission (Kamiya et al., 1996; Nicoll and Schmitz, 2005). Data were included only if the DCG-IV-insensitive response was $<10 \%$ of the initial baseline amplitude. Mossy fiber LTP was induced by a single tetanus $(25 \mathrm{~Hz}$ for $5 \mathrm{~s}$ ) in the presence of an NMDA-type glutamate receptor antagonist (50 $\mu \mathrm{M}$ APV) from $5 \mathrm{~min}$ before to $2 \mathrm{~min}$ following tetanic induction (Castillo et al., 2002). Mossy fiber LTP is reported as the average fEPSP amplitude during the 50-60 min post-tetanus period relative to the $10 \mathrm{~min}$ baseline period. Data were acquired at $10 \mathrm{kHz}$ and filtered at $1 \mathrm{kHz}$.

Data analysis. All summary data are presented as the mean percentage of the baseline. Error bars and values refer to SEM. Degree of mfLTP or STP did not significantly differ among mice within each viral manipulation (ANOVA, data not shown). Results from individual slices were used for statistical comparisons. ANOVA tests were performed on manipulations within the same genotype (43 slices, 4 viruses in RIM $1 \alpha^{+/+}$mice, $p=0.0008$; 29 slices, 3 viruses in RIM1 $\alpha^{-1-}$ mice, $p=0.04$; mfLTP experiments) before subsequent $a d$ hoc comparisons with Student's $t$ test. $p$ values from Student's $t$ test are reported, unless indicated otherwise. In all figures, an asterisk $\left(^{*}\right)$ indicates $p$ value $<0.05$ versus EGFP control.

\section{Results}

The 1-451 fragment of Munc13-1 inhibits mossy fiber LTP

In prior studies, expression of the 1-451 Munc13-1 fragment in autaptic cultured hippocampal pyramidal neurons reduced synaptic vesicle priming and the amplitude of evoked excitatory synaptic responses (Betz et al., 2001), demonstrating that this fragment is biologically active in inhibiting known functions of Munc13-1. This region of Munc13-1 includes the $\mathrm{C}_{2} \mathrm{~A}$ domain that confers RIM-binding, but none of the other defined functional domains (Fig. 1A) (Betz et al., 2001; Basu et al., 2005). To test the role of Munc13-1 in mfLTP, we acutely expressed Munc13-1 (1-451) in hippocampal granule cells of wild-type mice by in vivo injection of a modified Sindbis virus (Kim et al., 2004) into the dentate gyrus. As previously reported (Yang and Calakos, 2010), we found that slices expressing control EGFP protein alone exhibited robust $\mathrm{mfLTP}$, measured by the response 50-60 min after induction (Fig. 1C,D) $(148 \pm 3 \%, 6$ slices/3 mice). In contrast, expression of Munc13-1 (1-451) sig- nificantly impaired mfLTP (Fig. $1 C, D$ ) $(119 \pm 6 \%, 11$ slices $/ 4$ mice; $p=0.0004$ vs EGFP control). These results identify a role for Munc13-1 in mfLTP and support the possibility that this effect might be mediated by its interaction with RIM.

\section{RIM1 $\alpha-$ Munc13 interaction is involved} in mossy fiber LTP

Because the N-terminal region of Munc13-1 has also been reported to associate with other active zone proteins besides RIM (Wang et al., 2009), we specifically tested the significance of the RIM1 $\alpha$-Munc13-1 interaction for mfLTP. In prior studies, a K144E/ K146E mutation of RIM1 $\alpha$ was shown to specifically abolish Munc13 binding without altering the binding of other proteins known to interact with the $\mathrm{N}$ terminus of RIM $\alpha$ (Dulubova et al., 2005). Therefore, we tested the effect of expressing mutant RIM $1 \alpha^{\mathrm{K} 144 / 146 \mathrm{E}}$ on mfLTP. Viral-mediated acute expression of mutant RIM $1 \alpha^{\mathrm{K} 144 / 146 \mathrm{E}}$ in hippocampal granule cells of wildtype mice significantly inhibited mfLTP (Fig. 1C,D) $(124 \pm 6 \%$, 13 slices $/ 5$ mice; $p=0.002$ vs EGFP control). Importantly, similar expression of wild-type RIM $1 \alpha$ protein had no effect on mfLTP (Fig. $1 C, D)(151 \pm 7 \%, 13$ slices $/ 9$ mice; $p=0.72$ vs EGFP, $p=$ 0.006 vs RIM $\left.1 \alpha^{\mathrm{K} 144 / 146 \mathrm{E}}\right)$. This result indicates that the observed mfLTP impairment is not due to exogenous, viral-mediated overexpression of active zone proteins, but specifically results from disrupting the RIM1 $\alpha$-Munc13 interaction. Thus far, two independent approaches demonstrate a role for Munc13-1 in mfLTP. Of note, the degree of mfLTP impairment is similar between slices expressing Munc13-1 (1-451) and those expressing $\mathrm{RIM} 1 \alpha^{\mathrm{K} 144 / 146 \mathrm{E}}(p=0.61)$, consistent with the idea that these two manipulations act through a common mechanism.

Because active zone proteins may alter short-term plasticity and such effects might occlude mfLTP, we further investigated whether changes in short-term plasticity were associated with the effect on mfLTP. Acute expression of RIM1 $\alpha^{\mathrm{K} 144 / 146 \mathrm{E}}$ in hippocampal granule cells did not alter paired-pulse ratios of fEPSPs or NMDAREPSCs across a range of interstimulus intervals (Fig. $1 E, F$ ) (fEPSP $p=0.22$; NMDAR-EPSC, $p=0.74$; ANOVA), frequency facilitation (Fig. $1 G$ ) (EGFP, $257 \pm 7 \%$; RIM1 $\alpha^{\mathrm{K} 144 / 146 \mathrm{E}}, 261 \pm 16 \%$; $p=0.86$ ), or sensitivity to the group II metabotropic glutamate receptor agonist DCG-IV (Fig. 1G). These findings demonstrate that impairment of $\operatorname{mfLTP}$ by RIM1 $\alpha^{\mathrm{K} 144 / 146 \mathrm{E}}$ is not associated with altered shortterm plasticity at mossy fiber synapses.

\section{RIM1 $\alpha-$ Munc13 interaction is required for rescue of $\mathrm{mfLTP}$ in $\operatorname{RIM} 1 \alpha^{-/-}$mice}

Experiments thus far provide evidence that disruption of the RIM1 $\alpha$-Munc13-1 interaction is sufficient to disrupt mfLTP in wild-type synapses. In prior studies, we reconstituted mfLTP in RIM1 $\alpha$ KO mice by acutely expressing wild-type RIM1 $\alpha$ protein (Yang and Calakos, 2010). Using this approach in the present study, we tested whether the interaction of RIM1 $\alpha$ with Munc13 was necessary for this reconstitution. First, we found that, as previously reported (Yang and Calakos, 2010), acute expression of wild-type RIM $1 \alpha$ protein rescued mfLTP, indicated by a sustained increase in response 50-60 min after induction (Fig. 2) $(\mathrm{RIM} 1 \alpha, 142 \pm 9 \%, 11$ slices/ 6 mice; EGFP control, $117 \pm 7 \%, 8$ slices/ 6 mice; $p=0.036)$. Second, we found that when mutant 
$\mathrm{RIM} 1 \alpha^{\mathrm{K} 144 / 146 \mathrm{E}}$ protein was expressed, this long-lasting increase in neurotransmission was not observed (Fig. 2) (124 $\pm 4 \%, 10$ slices/ 6 mice; $p=0.38$ vs EGFP control). These findings show that an interaction between Munc13 and RIM1 $\alpha$ is required to restore $\mathrm{mfLTP}$.

\section{Discussion}

Presynaptic forms of long-term synaptic plasticity are expressed widely throughout the brain and are likely substrates for learning, memory and adaptive behaviors. Here we identify for the first time a role for Munc13 proteins in presynaptic long-term plasticity. Munc13-1 is required for vesicle priming (Rizo and Rosenmund, 2008), and more recent evidence indicates that RIM1 $\alpha$ 's interaction with Munc13-1 is a key regulator of this process (Deng et al., 2011). Because our results show that interaction with RIM1 $\alpha$ is required for Munc13-1's effects on mfLTP, our results also suggest that modulation of vesicle priming is a likely cellular basis for the change in presynaptic release probability that underlies mfLTP.

Munc13 proteins are required for making synaptic vesicles competent for release, a process commonly referred to as "priming” (Augustin et al., 1999). In the absence of full-length Munc13 proteins (Munc13-1 and Munc13-2 double KO mice), no vesicle priming was detected in hippocampal excitatory synapses of autaptic cultured pyramidal neurons (Varoqueaux et al., 2002). A domain sufficient for vesicle priming has been defined in the C-terminal region of Munc13 (Betz et al., 2001; Basu et al., 2005; Stevens et al., 2005). Although the N-terminal (1-451) region of Munc13-1 did not have priming activity (Betz et al., 2001), it may regulate vesicle priming. Expression of the 1-451 region in wildtype autaptic cultured pyramidal neurons inhibited vesicle priming (Betz et al., 2001). RIM proteins are also implicated in vesicle priming, but current data point to a regulatory rather than essential role. In mice lacking full-length RIMs, vesicle priming was reduced at hippocampal excitatory synapses of autaptic cultured pyramidal neurons (50\% reduction in RIM1 $\alpha$ KO mice) (Calakos et al., 2004) and at inhibitory synapses of cultured hippocampal neurons (70\% reduction in RIM1 and RIM2 double KO mice) (Deng et al., 2011; Kaeser et al., 2011). Most recently, direct evidence that RIM regulates the amount of vesicle priming and does so through its interaction with the Munc13 $\mathrm{C}_{2} \mathrm{~A}$ domain has been reported (Deng et al., 2011).

Altogether, these results predict that the RIM1 $\alpha-$ Munc13-1 interaction that we disrupt in the present study might alter the amount of primed vesicles, either basally or the dynamic regulation thereof. We did not find evidence that vesicle priming was altered basally because such a disruption would alter short-term plasticity (Zucker and Regehr, 2002) and short-term plasticity was not affected when the RIM $1 \alpha$-Munc13 interaction was disrupted (Fig. $1 E-G$ ). Rather, we observed functional effects of disrupting the RIM1 $\alpha$-Munc13-1 interaction only under conditions where synaptic strength was dynamically regulated, i.e., in mfLTP. Our results in combination with prior observations suggest that the role of the RIM1 $\alpha$-Munc13-1 interaction may differ between synapse types-being important for basal release in pyramidal synapses (Betz et al., 2001) and long-term plasticity in mossy fiber synapses. Such a possibility is consistent with prior observations that RIM $1 \alpha$ deletion impaired long-term but not short-term plasticity at mossy fiber synapses (Castillo et al., 2002) yet impaired release probability and short-term plasticity at pyramidal synapses (Schoch et al., 2002).

Dynamic regulation of the amount of primed vesicles is a plausible mechanism to achieve the change in synaptic release probability that is associated with presynaptic LTP (Weisskopf and Nicoll, 1995) because the amount of primed vesicles positively correlates with synaptic release probability (Dobrunz and Stevens, 1997; Hanse and Gustafsson, 2001). While this is plausible, our current results are unable to discriminate between effects on induction and expression of LTP, nor are they able to determine whether the effects are indeed through the actions of the RIM1 $\alpha$-Munc13-1 interaction on vesicle priming as opposed to another, as yet undefined, function for this interaction. Last, while one manipulation selectively altered Munc13-1, the RIM1 $\alpha$ mutation disrupts RIM1 $\alpha$ binding to both Munc13-1 and Munc13-2 (Dulubova et al., 2005; Deng et al., 2011). However, the interpretation of our results is facilitated by recent observations that demonstrate that Munc13-2 does not have a role in LTP at mossy fiber synapses (Breustedt et al., 2010). In summary, our study clearly defines a role for the RIM1 $\alpha$-Munc13-1 interaction in mfLTP. Further testing of the cellular consequences of this interaction will require technical advances to enable monitoring of primed vesicles in brain slices and single synaptic release events at mossy fiber terminals.

A separate revealing observation in the present study is that overexpression of wild-type RIM1 $\alpha$ in wild-type neurons neither occludes nor augments mfLTP. The lack of mfLTP occlusion by RIM $1 \alpha$ overexpression supports previous observations that RIM1 $\alpha$ has no significant contribution to basal release properties or short-term plasticity at these synapses (Castillo et al., 2002; Yang and Calakos, 2010). The lack of mfLTP augmentation by overexpressing RIM1 $\alpha$ in wild-type neurons indicates that protein levels of RIM $1 \alpha$ do not influence the magnitude of mfLTP. This observation suggests that another constraint for the magnitude of mfLTP exists other than protein expression levels of RIM1 $\alpha$.

Finally, although presynaptic long-term plasticity is widely expressed, molecular dissection of mechanisms underlying presynaptic forms has lagged behind the study of postsynaptic mechanisms for long-term synaptic plasticity, partly because of technical challenges. Using an approach that can acutely genetically modify synapses in vivo and can modify sufficient numbers of presynaptic inputs so that measuring synaptic transmission via the postsynaptic response is not significantly confounded by unmodified inputs, we have been able to identify a new mediator of presynaptic LTP. In the past, proteins have been implicated in presynaptic plasticity through study of gene knockout models (Castillo et al., 1997, 2002; Villacres et al., 1998; Breustedt et al., 2010)_an approach that is not possible for the study of Munc13-1 because knock-out mice are inviable, and gene deletion eliminates neurotransmission. Thus, in vivo genetic manipulation of mossy fiber synapses provides a unique opportunity for interrogating protein functions in presynaptic LTP and reveals in this study a previously unknown role for Munc13-1 in presynaptic LTP.

\section{References}

Augustin I, Rosenmund C, Südhof TC, Brose N (1999) Munc13-1 is essential for fusion competence of glutamatergic synaptic vesicles. Nature 400:457-461.

Basu J, Shen N, Dulubova I, Lu J, Guan R, Guryev O, Grishin NV, Rosenmund C, Rizo J (2005) A minimal domain responsible for Muncl3 activity. Nat Struct Mol Biol 12:1017-1018.

Basu J, Betz A, Brose N, Rosenmund C (2007) Munc13-1 C1 domain activation lowers the energy barrier for synaptic vesicle fusion. J Neurosci 27:1200-1210.

Betz A, Thakur P, Junge HJ, Ashery U, Rhee JS, Scheuss V, Rosenmund C, Rettig J, Brose N (2001) Functional interaction of the active zone proteins Munc13-1 and RIM1 in synaptic vesicle priming. Neuron 30:183-196. 
Breustedt J, Gundlfinger A, Varoqueaux F, Reim K, Brose N, Schmitz D (2010) Munc13-2 differentially affects hippocampal synaptic transmission and plasticity. Cereb Cortex 20:1109-1120.

Calakos N, Schoch S, Südhof TC, Malenka RC (2004) Multiple roles for the active zone protein RIM1alpha in late stages of neurotransmitter release. Neuron 42:889-896.

Castillo PE, Janz R, Südhof TC, Tzounopoulos T, Malenka RC, Nicoll RA (1997) Rab3A is essential for mossy fibre long-term potentiation in the hippocampus. Nature 388:590-593.

Castillo PE, Schoch S, Schmitz F, Südhof TC, Malenka RC (2002) RIMlalpha is required for presynaptic long-term potentiation. Nature 415:327-330.

Deng L, Kaeser PS, Xu W, Südhof TC (2011) RIM proteins activate vesicle priming by reversing autoinhibitory homodimerization of Munc13. Neuron 69:317-331.

Dobrunz LE, Stevens CF (1997) Heterogeneity of release probability, facilitation, and depletion at central synapses. Neuron 18:995-1008.

Dulubova I, Lou X, Lu J, Huryeva I, Alam A, Schneggenburger R, Südhof TC, Rizo J (2005) A Munc13/RIM/Rab3 tripartite complex: from priming to plasticity? EMBO J 24:2839-2850.

Fourcaudot E, Gambino F, Humeau Y, Casassus G, Shaban H, Poulain B, Lüthi A (2008) cAMP/PKA signaling and RIMlalpha mediate presynaptic LTP in the lateral amygdala. Proc Natl Acad Sci U S A 105:15130-15135.

García-Junco-Clemente P, Linares-Clemente P, Fernández-Chacón R (2005) Active zones for presynaptic plasticity in the brain. Mol Psychiatry 10:185-200; image 131 .

Hanse E, Gustafsson B (2001) Vesicle release probability and pre-primed pool at glutamatergic synapses in area CAl of the rat neonatal hippocampus. J Physiol 531:481-493.

Heifets BD, Castillo PE (2009) Endocannabinoid signaling and long-term synaptic plasticity. Annu Rev Physiol 71:283-306.

Huang YY, Li XC, Kandel ER (1994) cAMP contributes to mossy fiber LTP by initiating both a covalently mediated early phase and macromolecular synthesis-dependent late phase. Cell 79:69-79.

Junge HJ, Rhee JS, Jahn O, Varoqueaux F, Spiess J, Waxham MN, Rosenmund C, Brose N (2004) Calmodulin and Munc13 form a Ca2+ sensor/effector complex that controls short-term synaptic plasticity. Cell 118:389-401.

Kaeser PS, Deng L, Wang Y, Dulubova I, Liu X, Rizo J, Südhof TC (2011) RIM proteins tether $\mathrm{Ca}(2+)$ channels to presynaptic active zones via a direct PDZ-domain interaction. Cell 144:282-295.

Kamiya H, Shinozaki H, Yamamoto C (1996) Activation of metabotropic glutamate receptor type $2 / 3$ suppresses transmission at rat hippocampal mossy fibre synapses. J Physiol 493:447-455.

Kim J, Dittgen T, Nimmerjahn A, Waters J, Pawlak V, Helmchen F, Schlesinger S, Seeburg PH, Osten P (2004) Sindbis vector SINrep(nsP2S726): a tool for rapid heterologous expression with attenuated cytotoxicity in neurons. J Neurosci Methods 133:81-90.

Marie H, Morishita W, Yu X, Calakos N, Malenka RC (2005) Generation of silent synapses by acute in vivo expression of CaMKIV and CREB. Neuron 45:741-752.

Nicoll RA, Schmitz D (2005) Synaptic plasticity at hippocampal mossy fibre synapses. Nat Rev Neurosci 6:863-876.

Rizo J, Rosenmund C (2008) Synaptic vesicle fusion. Nat Struct Mol Biol 15:665-674.

Rosenmund C, Sigler A, Augustin I, Reim K, Brose N, Rhee JS (2002) Differential control of vesicle priming and short-term plasticity by Munc13 isoforms. Neuron 33:411-424.

Salin PA, Malenka RC, Nicoll RA (1996) Cyclic AMP mediates a presynaptic form of LTP at cerebellar parallel fiber synapses. Neuron 16:797-803.

Schoch S, Castillo PE, Jo T, Mukherjee K, Geppert M, Wang Y, Schmitz F, Malenka RC, Südhof TC (2002) RIMlalpha forms a protein scaffold for regulating neurotransmitter release at the active zone. Nature 415:321-326.

Shin OH, Lu J, Rhee JS, Tomchick DR, Pang ZP, Wojcik SM, Camacho-Perez M, Brose N, Machius M, Rizo J, Rosenmund C, Südhof TC (2010) Munc13 C2B domain is an activity-dependent $\mathrm{Ca} 2+$ regulator of synaptic exocytosis. Nat Struct Mol Biol 17:280-288.

Stevens DR, Wu ZX, Matti U, Junge HJ, Schirra C, Becherer U, Wojcik SM, Brose N, Rettig J (2005) Identification of the minimal protein domain required for priming activity of Munc13-1. Curr Biol 15:2243-2248.

Varoqueaux F, Sigler A, Rhee JS, Brose N, Enk C, Reim K, Rosenmund C (2002) Total arrest of spontaneous and evoked synaptic transmission but normal synaptogenesis in the absence of Munc13-mediated vesicle priming. Proc Natl Acad Sci U S A 99:9037-9042.

Villacres EC, Wong ST, Chavkin C, Storm DR (1998) Type I adenylyl cyclase mutant mice have impaired mossy fiber long-term potentiation. J Neurosci 18:3186-3194.

Wang X, Hu B, Zieba A, Neumann NG, Kasper-Sonnenberg M, Honsbein A, Hultqvist G, Conze T, Witt W, Limbach C, Geitmann M, Danielson H, Kolarow R, Niemann G, Lessmann V, Kilimann MW (2009) A protein interaction node at the neurotransmitter release site: domains of Aczonin/Piccolo, Bassoon, CAST, and rim converge on the N-terminal domain of Munc13-1. J Neurosci 29:12584-12596.

Wang Y, Okamoto M, Schmitz F, Hofmann K, Südhof TC (1997) Rim is a putative Rab3 effector in regulating synaptic-vesicle fusion. Nature 388:593-598.

Weisskopf MG, Nicoll RA (1995) Presynaptic changes during mossy fibre LTP revealed by NMDA receptor-mediated synaptic responses. Nature 376:256-259.

Weisskopf MG, Castillo PE, Zalutsky RA, Nicoll RA (1994) Mediation of hippocampal mossy fiber long-term potentiation by cyclic AMP. Science 265:1878-1882

Yang Y, Calakos N (2010) Acute in vivo genetic rescue demonstrates that phosphorylation of RIM1 $\alpha$ serine 413 is not required for mossy fiber long-term potentiation. J Neurosci 30:2542-2546.

Zucker RS, Regehr WG (2002) Short-term synaptic plasticity. Annu Rev Physiol 64:355-405. 